\title{
Mantle heterogeneity beneath eastern California from magnetotelluric measurements
}

\author{
Stephen K. Park \\ Institute of Geophysics and Planetary Physics, University of California, Riverside, California, USA \\ Received 19 December 2003; revised 3 May 2004; accepted 6 July 2004; published 29 September 2004.
}

[1] A $300 \mathrm{~km}$ long magnetotelluric profile across the Great Valley, Sierra Nevada, and California Basin and Range reveals minimum resistivity differences of 1 order of magnitude at depths from Moho at $30-35 \mathrm{~km}$ to depths greater than $200 \mathrm{~km}$. Horizontal wavelengths of $25 \mathrm{~km}$ are seen for these changes at depths shallower than $100 \mathrm{~km}$, and the Isabella high seismic wave speed anomaly is present in the section between depths of 100 and $200 \mathrm{~km}$ as a minimum tenfold resistivity increase. A transformation from electrical resistivity to temperature and melt fraction using a petrological model and laboratory measurements reveals that partial melt is relatively uncommon and confined primarily to depths between 30 and $100 \mathrm{~km}$. The remainder of the observed resistivity variation is attributed to lateral variations in temperature. Predicted melt fractions match those inferred from Miocene-Quaternary xenoliths, but modeled temperatures are $\sim 200^{\circ} \mathrm{C}$ higher than inferred from thermobarometric analyses of the xenoliths. Possible causes for this discrepancy include an incorrect starting material for the petrological model, exotic conductive phases, higher conductivity due to oxidation state and/or iron content, and diffusion of ions through the solid matrix. I show that hydrogen diffusion or higher oxygen concentrations are plausible explanation for the higher model temperatures. Less than $200 \mathrm{ppm} \mathrm{H} / 10^{6} \mathrm{Si}$ in olivine would increase the conductivity of the matrix sufficiently to allow temperatures inferred from the resistivity section to match those from the xenoliths. A possible source of the hydrogen would be fragments of sinking, metasomatized mantle lithosphere that melted during Cenozoic delamination. INDEX TERMS: 8124 Tectonophysics: Earth's interior-composition and state (1212); 8109 Tectonophysics: Continental tectonics - extensional (0905); 0925 Exploration Geophysics: Magnetic and electrical methods; 3914 Mineral Physics: Electrical properties; 5109 Physical Properties of Rocks: Magnetic and electrical properties; KEYWORDS: magnetotelluric method, Death Valley, Sierra Nevada, petrology, electrical conductivity

Citation: Park, S. K. (2004), Mantle heterogeneity beneath eastern California from magnetotelluric measurements, J. Geophys. Res., 109, B09406, doi:10.1029/2003JB002948.

\section{Introduction}

[2] The juxtaposition of elevations in excess of $4000 \mathrm{~km}$ above sea level (asl) on the flanks of an active belt of continental extension has led to questions of how the high elevations are supported. The Southern Sierra Continental Dynamics project in 1993 [e.g., Park et al., 1995] and the Sierran Paradox experiment in 1997 (Figure 1) revealed that the southern Sierra Nevada lack a crustal root and are instead supported by partially melted asthenosphere [Wernicke et al., 1996]. Low mantle seismic velocities [Ruppert et al., 1998], xenolith thermobarometry [Ducea and Saleeby, 1996, 1998b], low electrical resistivities [Park et al., 1996], and basalt geochemistry [Farmer et al., 2002] all confirm that the mantle lithosphere is missing in this region and that the asthenosphere is directly beneath granitoid crust at a depth of approximately $35 \mathrm{~km}$. Geological and geochemical

Copyright 2004 by the American Geophysical Union. 0148-0227/04/2003JB002948\$09.00 studies of the xenoliths and basalts show that a mantle lithosphere at least $70 \mathrm{~km}$ thick was present beneath the granitoid crust at $8 \mathrm{Ma}$ but was lost by $3.5 \mathrm{Ma}$ [Ducea and Saleeby, 1998b; Ducea, 2002].

[3] The composition of the missing component of the lithosphere is likely eclogitic. Eclogite xenoliths are found in 12-8 Ma basalts of the San Joaquin and King volcanic fields. Assuming a basaltic andesite bulk composition for the Mesozoic arc magmatism during the time of formation of the Sierran batholiths, Ducea and Saleeby [1998b] estimate that an eclogitic residue 1-2 times as thick as the granitoid crust would have developed. Because the granitoid crust is $\sim 35 \mathrm{~km}$ thick [Fliedner et al., 1996], this calculation indicates an eclogitic root of $35-70 \mathrm{~km}$ during Miocene times. Further, isotopic studies of $3.5 \mathrm{Ma}$ basalts show that the eclogite was removed and not metamorphosed [Farmer et al., 2002; Manley et al., 2000]. Such an eclogitic root would be gravitationally unstable, so loss via delamination [Bird, 1978] or convective removal [Houseman et al., 1981] seems plausible. 
[4] If the mantle lithosphere was physically removed between 8 and $4 \mathrm{Ma}$, then traces of it should be identifiable in the mantle with geophysical methods. A region of anomalously high mantle velocities lies west of the area where thinning of the mantle lithosphere is documented [e.g., Benz and Zandt, 1993; Jones et al., 1994]. Velocities in this "Isabella anomaly" are $>3 \%$ higher than the surrounding mantle [Benz and Zandt, 1993]. The anomaly is areally restricted, however (Figure 1), suggesting lateral migration of mantle lithosphere to the west [Zandt, 2003]. The eastern edge of the Isabella anomaly coincides approximately with the boundary between low heat flow $\left(18-21 \mathrm{~mW} / \mathrm{m}^{2}\right)$ to the west and higher heat flow values $\left(32-57 \mathrm{~mW} / \mathrm{m}^{2}\right)$ more characteristic of the Basin and Range to the east [Saltus and Lachenbruch, 1991]. The upwelling mantle lies east of the Isabella anomaly where the heat flow is higher. As will be shown here, the Isabella anomaly also has high electrical resistivity.

[5] Results of a broadband and long-period MT study of the Sierra Nevada and California Basin and Range are presented here. I first explain how a resistivity cross section is derived from the MT data and discuss bounds on that section. The section shows that the mantle is strongly heterogeneous, complicating its interpretation. I then use a petrological model combined with laboratory measurements to separate the effects of partial melt and temperature in the resistivity section and show that partial melt is much less prevalent than would normally be inferred from the resistivity section. I finally compare the temperatures and partial melt fractions predicted to those estimated from xenoliths and discuss reasons for discrepancies.

\section{Magnetotelluric Studies}

[6] Time varying magnetic fields at the surface induce small electric fields in the Earth that are distributed by heterogeneous conductivity structure. The magnetotelluric method monitors these fields at periods from $0.001 \mathrm{~s}$ to over $20,000 \mathrm{~s}$ in order to determine the electrical impedance and magnetic transfer function of the Earth (see Vozoff [1991] for a review of the method). The complex, period-dependent impedance is a tensor relating the vector horizontal electric and magnetic fields. The tensor is typically decomposed into two principal orthogonal impedances. These two impedances, usually called the transverse magnetic (TM) and transverse electric (TE) modes, are perpendicular and parallel to local geologic strike, respectively, if the structure is approximately two-dimensional (2-D). Because threedimensional (3-D) inversion is not yet publicly available, data are usually inverted with 2-D inversions to yield an electrical resistivity cross section perpendicular to strike [e.g., Rodi and Mackie, 2001]. The TM and TE modes respond to different aspects of the structure, and errors can arise when using 2-D models to interpret 3-D data. The TE mode is sensitive to conductive bodies parallel to strike and can be distorted by truncation of those bodies along strike [Wannamaker, 1999], as would happen in 3-D structures. The TM mode is more sensitive to resistivity contrasts with strikes parallel to geologic strike and is less sensitive to truncation of those structures, so typical 2-D inversions weight the TM mode more heavily. Both modes over truncated resistive structures are less sensitive to end effects

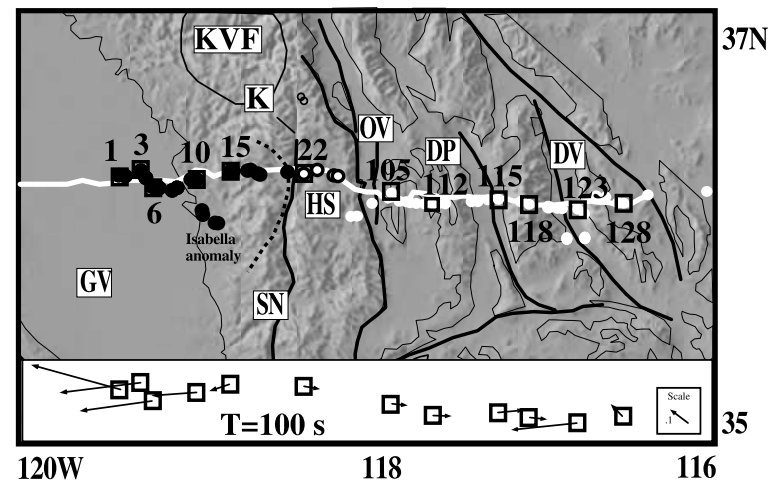

Figure 1. Location map of southern Sierra Nevada showing MT sites. Solid dots are broadband sites from Park et al. [1996], and white dots are from Park and Wernicke [2003]. Solid squares with site numbers are longperiod sites used in this study. Inset at bottom shows induction arrows at sites for a period of $100 \mathrm{~s}$. White line is SSCD seismic line, and dashed line shows eastern edge of Isabella anomaly. Kern volcanic field (KVF) is the source of some xenoliths. Crystalline outcrops are outlined with thin black lines; major faults are heavier lines. Other symbols shown are DP, Darwin Plateau; DV, Death Valley; GV, Great Valley; HS, High Sierra; K, Kern River fault; OV, Owens Valley; and SN, Sierra Nevada.

and 3-D bodies can be approximated with 2-D models without major errors [Berdichevsky, et al., 1998].

[7] Just as the impedance relates the horizontal electric fields to the horizontal magnetic fields, the magnetic transfer function relates the vertical to the horizontal magnetic fields [Schmucker, 1970]. While this sensitivity is similar to that of the TE mode, these functions are also similar to the TM mode because they are less sensitive to truncation of these conductors along strike. Thus these functions are usually weighted almost as heavily in 2-D inversion as is the TM mode [Wannamaker, 1999]. The transfer functions are often represented as induction vectors that show the direction of the greatest correlation between the vertical and horizontal magnetic fields. We normally plot the real components of the induction vectors (Figure 1), which usually point toward 2-D conductors [Schmucker, 1970].

[8] Electromagnetic energy diffuses, rather than propagates as a wave, into the conducting Earth. Longer periods thus penetrate deeper into the Earth. The principal complex impedances are transformed into magnitudes and phases and plotted versus period to create a pseudosection (Figure 2) with short periods (proxy for shallow depths) at the top. The magnitudes are converted to apparent resistivities for ease of visual analysis and discussion. The pseudosections cannot be transformed directly into depth sections because the depth of penetration of the electromagnetic energy depends also on the resistivity through which the energy diffuses. Instead, 2-D modeling is used to find structures that reproduce the observed pseudosections.

[9] Data used for this study were acquired from 1993 to 1997 and consist of 54 commercially acquired broadband soundings and 12 long-period soundings collocated with selected broadband stations (see Park et al. [1996] and Park and Wernicke [2003] for details of surveys). All data were 

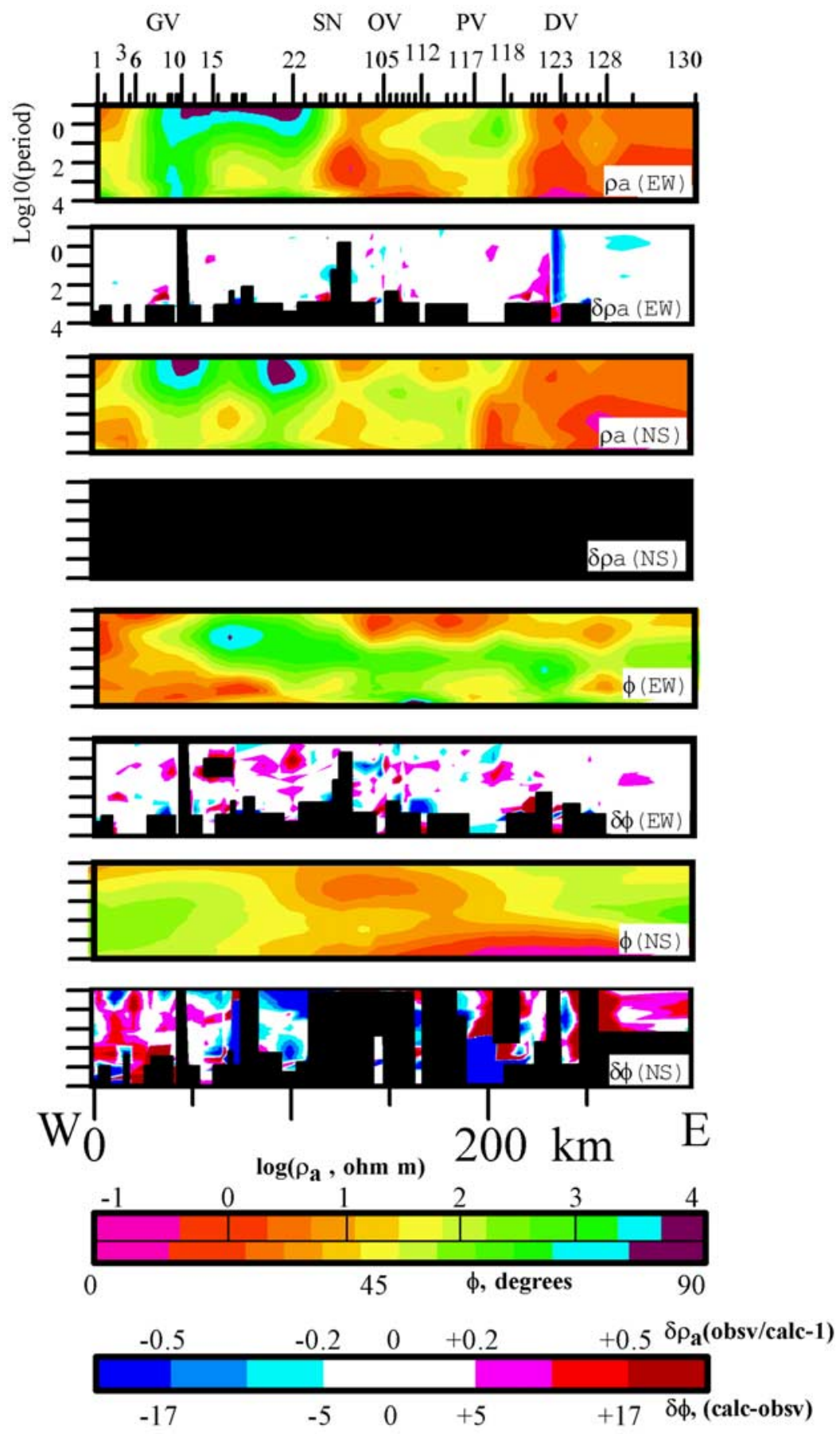

Figure 2. Pseudosections of MT data and associated fits to data from final model. Each section is labeled with the type of data (apparent resistivity in ohm $\mathrm{m}$ or phase) and its orientation (N-S or E-W). Color scales for apparent resistivities and phases are shared, but ranges are labeled differently for these quantities. Similarly, scales for difference pseudosections for apparent resistivity and phase are shared but ranges are different. Sections of data excluded from the inversion are shown with black areas in difference pseudosections. Note that most of the TE phases and all of the TE apparent resistivities (i.e., the N-S mode) were not used in the inversion. The E-W pseudosections show no systematic misfits, and the large misfits on the N-S phases are due to the larger error floors for this component.

acquired using remote referencing to reduce the effects of noise. The commercial data were acquired at periods from 0.008 to $1,000 \mathrm{~s}$ with the Phoenix V5 system, while the long-period data at periods from 20 to $20,000 \mathrm{~s}$ were acquired with LIMS (long period magnetotelluric systems) from the Geological Survey of Canada (Figure 1, stations $1-15$ ) and the University of Washington (stations 22, 105128). Only cross-power spectra and transfer functions were provided with the commercial data, which were processed with a proprietary cascade decimation program. The long- 
period data were processed with a robust analysis [Chave et al., 1987] both with and without remote referencing; the remote referencing made no apparent difference for the long-period data.

[10] Data quality from the broadband soundings was relatively poor at periods beyond $200 \mathrm{~s}$, so the long-period stations provide the primary data for this study of the mantle. Additionally, the only reliable vertical magnetic transfer functions came from the long-period stations. Because of the delay between the broadband and longperiod surveys, collocation of sites was not exact. Thus long-period impedance magnitudes were shifted by factors of 1 to 5 to match those from the broadband stations; see Park and Wernicke [2003] for a detailed description of the shift process. Broadband static shift corrections used by Park et al. [1996] and Park and Wernicke [2003] are applied to the merged data in this study (these references explain how the shifts were derived and provide tables of the applied shifts).

[11] Previous interpretations of these MT data have either been limited by computer capabilities [Park et al., 1996] or have focused only on the correlation of the crustal electrical resistivity section with surface geology [Park and Wernicke, 2003]. Park et al. [1996] used the Rapid Relaxation Inverse (RRI) method [Smith and Booker, 1991] on broadband data in the Sierra Nevada and Great Valley to delineate batholithic structure and show that the uppermost mantle has a few percent partial melt. The broadband data were unreliable at the periods needed to examine the mantle below $50-$ $100 \mathrm{~km}$, however, and no long-period data were available for their study. Park and Wernicke [2003] used the data east of the Sierra Nevada to develop a crustal resistivity model that could be correlated with a geological cross section. Because of size limits on the 2-D model, their detailed crustal model did not extend to the west where Park et al. [1996] had worked and did not optimize gridding for the mantle structure. While the later study included long-period data and vertical magnetic transfer functions, it did not have the aperture (i.e., width) to accurately image mantle structures.

\section{Two-Dimensional Modeling}

[12] This study uses all long-period and broadband data sets available from the earlier studies. Impedance tensors corrected for the effects of very shallow 3-D heterogeneity [e.g., Groom and Bailey, 1989] are taken from Park et al. [1996] and Park and Wernicke [2003]. Rodi and Mackie's [2001] 2-D inversion is used to model these data. The coincidence of the average geoelectrical strike $\left(\mathrm{N} 10^{\circ} \mathrm{W}\right)$ with geologic strike and orientation of the induction vectors perpendicular to geologic strike led Park et al. [1996] and Park and Wernicke [2003] to conclude that the use of a 2-D model was valid. For this and the earlier studies, the E-W impedance is identified as the TM mode and the N-S impedance is the TE mode. The 2-D inversion jointly fits the observed impedance elements and magnetic transfer functions and smooths the model $[\rho(x, z)]$ via minimization of the following functional: $\|$ (observed data - calculated responses $)\left\|^{2}+\right\| \nabla^{2}$ (model - a priori model $) \|^{2}$. The second term penalizes smooth variations of the final model from an a priori one. The MT inversion process is fundamentally
Table 1. A Priori Layered Model

\begin{tabular}{cc}
\hline Depth Interval, $\mathrm{km}$ & Layer Resistivity, ohm m \\
\hline $0-20$ & 2000 \\
$20-50$ & 1000 \\
$50-90$ & 500 \\
$90-05$ & 200 \\
$105-200$ & 100 \\
$200-490$ & 10 \\
$490+$ & 1 \\
\hline
\end{tabular}

underdetermined (more blocks of unknown resistivity than observations), so the model smoothing helps constrain the final result. It is possible to bias the final result with the starting model, however, and I therefore used the layered half-space in Table 1 as the a priori model. This layered model was determined using 1-D inversion of the determinant of the impedance tensor at a site chosen to be representative of all sites. In other words, it was chosen as an appropriate average for all sites on the profile. Layers shallower than $200 \mathrm{~km}$ were chosen from the 1-D inversion, and deeper resistivities were based on Swift's [1967] study of the southwest United States. Because a layered model lacks any lateral changes, lateral variations in the final model are penalized by the smoothness constraints and are required to fit the data. In this manner, I tried to guarantee a maximally smooth model in the upper $200 \mathrm{~km}$.

[13] The gridded model had 218 horizontal and 86 vertical cells with lateral changes in width of less than a factor of 1.5 between any adjacent cells in order to satisfy Rodi and Mackie's [2001] modeling constraints. Only a subset of the model will be shown here; the full model extended 10,000 $\mathrm{km}$ to the east and west and included the conductive Pacific Ocean. On the basis of test models with and without topography, shifts of apparent resistivities of up to a factor of $\sim 2$ were caused by $4080 \mathrm{~m}$ of relief along the MT profile. Topography was thus added in the model with 45 of the 86 vertical cells. Size limitations in the program prevented more layers in the model and the large number of vertical layers needed for the topography prevented simultaneously gridding the crust as finely as did Park and Wernicke [2003] and including sufficient layers to delineate mantle structure between 30 and $200 \mathrm{~km}$. I thus compromised by emphasizing the mantle and generalizing the crustal layering used by Park and Wernicke [2003]. Because the crustal layers below the topography were thicker, data at periods shorter than $0.1 \mathrm{~s}$ (which respond mostly to fine details of the structure in the upper $1-5 \mathrm{~km}$ ) were excluded from the inversion.

[14] An adjustable parameter $(\tau)$ specifies the relative weight between the data misfit and the deviation from the a priori model. A larger value places more weight on the model constraints and generates a smoother model at the expense of data fits; a smaller one yields a rougher model and better data fits. After several trials, a $\tau$ of 1.0 was chosen to maximize model smoothness and minimize data misfit.

[15] Individual data are weighted in the inversion by the inverse of their variances [Rodi and Mackie, 2001]. Because formal errors from the time series analysis were often smaller than the scatter of the impedance estimates between adjacent periods, this scatter was used to establish minimum uncertainties of $5 \%$ in E-W (TM) apparent resistivity and $0.05 \mathrm{rad}\left(2.8^{\circ}\right)$ in E-W phase. Larger error floors of $0.2 \mathrm{rad}$ 
$\left(11.2^{\circ}\right)$ for the $\mathrm{N}-\mathrm{S}$ phase reflected larger scatter in these data and the expected greater influence from 3-D structure north or south of the profile. Note that no models were found that would satisfactorily fit the N-S apparent resistivity and the other data, so these data were not used in the final result. Finally, an error floor of $20 \%$ was chosen for the magnetic transfer functions based on the quality of the longperiod data.

[16] The inversion converged with average errors 2.1 times larger (RMS error of 2.10) than my estimates of the data uncertainties after 98 iterations, yielding the model in Figure 3. Fits to the E-W mode (Figure 2) and the magnetic transfer functions (Figure 4) show good overall fits, with misfits due largely to single data points at various sites. Magnitudes of the magnetic transfer functions were generally less than 0.2 , and the model predicted low magnitudes even where the data were not fit exactly (Figure 4). The fit to the N-S phase was more problematic, however. Much of this phase data in the center of the line (sites 101-115) were excluded from the inversion because of instrumental problems; the commercial broadband data were recorded in two period bands and there was an abrupt shift in the phases at the boundary between the two bands. Wannamaker et al. [2004] has shown recently that a similar shift could be due to a DC power line in Owens Valley, but the shift due to an external cause appearing at the band boundary seems too coincidental. Additionally, several sites $(14,20,117,118)$ had marked departures from minimum phase behavior and were thus excluded (Figure 2). The N-S phases at the remaining sites are not fit as well as the E-W phases because of the larger error floor for these data.

[17] The model exhibits both the crustal heterogeneity noted in previous studies [Park et al., 1996; Park and Wernicke, 2003] and significant mantle heterogeneity. Unlike the mantle model of Park et al. [1996], the conductive body immediately below Moho (white line in Figure 3) does not extend eastward beneath the Basin and Range. The mantle between Moho and $100 \mathrm{~km}$ depth instead consists of alternating blocks of high and low resistivities. This heterogeneity is observed to depths of almost $240 \mathrm{~km}$ with higher resistivities to the west corresponding to the Isabella anomaly and lower resistivities to the east beneath the encroaching Basin and Range (Figure 3). There is some sensitivity to conductivity below $240 \mathrm{~km}$ where the structure becomes much more uniform. Thus the lower boundary of the Isabella anomaly at $\sim 250 \mathrm{~km}$ [Zandt, 2003] appears in the MT data as a transition to a more conductive and uniform mantle below it. The mantle heterogeneity should be a robust feature of the model because lateral change is penalized in the inversion. Further, there appear to be few artifacts of the layered structure from Table 1 preserved in the preferred model. I therefore conclude that the a priori model has not significantly biased the preferred model.

[18] Formal uncertainty bounds for the resistivity elements in Figure 3 are theoretically calculable in the inversion but are generally meaningless because the system is underdetermined and because sensitivity to model blocks is based on the current density in the block. That current density is, in turn, determined by the interaction of that block with the rest of the rest of the model. Sensitivity to, and thus uncertainty in, a particular resistivity will therefore change for different models. MT inversions currently do not provide formal bounds on the resistivities of the blocks. Instead, sensitivity testing is employed to establish bounds on the preferred model. In these tests, multiple inversions are run with portions of the model held fixed in order to conduct a limited exploration of parameter space. If an alternative model is found that fits the data with the errors as well as the preferred model, then both models are plausible [Park et al., 1996]. Successive tests of the same fixed region with different resistivities are used to determine when data fits are no longer acceptable, thus establishing limits on the resistivities of the fixed region. The bounds so determined in Figure 3 are for uniform resistivity within the outlined region and do not reflect the internal heterogeneity shown in each region because sensitivity testing for each resistivity cell would be prohibitive in time and memory. The bounds are one sided in many cases because the overall model sets limits on the amount of current that can be attracted (in the case of a conductor) or repelled (in the case of a resistor).

[19] The mantle heterogeneity discussed above is significant at the scale of the regions in Figure 3. Conductive upper mantle lies beneath the High Sierra (sites 22-25; Figure 3) and Darwin Plateau (sites 106-113), while more resistive mantle lies beneath the eastern Great Valley and Sierran foothills (sites 1-20), Owens Valley (sites 25-105), and Panamint Valley and Range (sites 114-120). Death Valley and regions east are underlain by generally more conductive mantle (sites 122-130; Figure 3). The most marked difference in the deeper mantle is a minimum of 1 order of magnitude resistivity increase across the eastern boundary of the Isabella anomaly.

[20] Three-dimensional effects cannot explain the high resistivity observed for the Isabella anomaly (Figure 3). While the model in Figure 3 was derived under an assumption that this resistive feature is 2-D, seismic evidence [e.g., Jones et al., 1994] suggests that the velocity anomaly has a limited lateral extent (Figure 1). Comparison of modeled responses at a site from a simplified version of the 2-D model in Figure 3 and its 3-D counterpart with the Isabella anomaly extending only $50 \mathrm{~km}$ north and south of the profile shows that the E-W mode is reduced only by a factor of 2 and the N-S mode is virtually unaffected by truncation at periods longer than $100 \mathrm{~s}$ (Figure 5). Such minimal differences between the 3-D responses and their 2-D approximations are consistent with those of Berdichevsky et al. [1998]. The model in Figure 3 is based primarily on the TM mode and the $\mathrm{Hz}$ data, so it is nonetheless possible that the resistivity of the Isabella anomaly is underestimated by forcing a 2-D model to fit the 3-D response. On the basis of comparison of these simple 2-D and 3-D models, a full $3-\mathrm{D}$ model would likely increase the resistivity contrast between the Isabella anomaly and the asthenospheric mantle beneath the High Sierra. This would make the difference between the upwelling mantle to the east and the remaining mantle lithosphere to the west even more marked.

\section{Petrological Modeling}

[21] In this section, I present a method for going beyond the resistivity section in Figure 3 and develop a systematic modeling approach using petrological modeling and laboratory measurements. The transition in terminology from resistivity in ohm $\mathrm{m}$ to conductivity in $\mathrm{S} / \mathrm{m}$ in this section is 


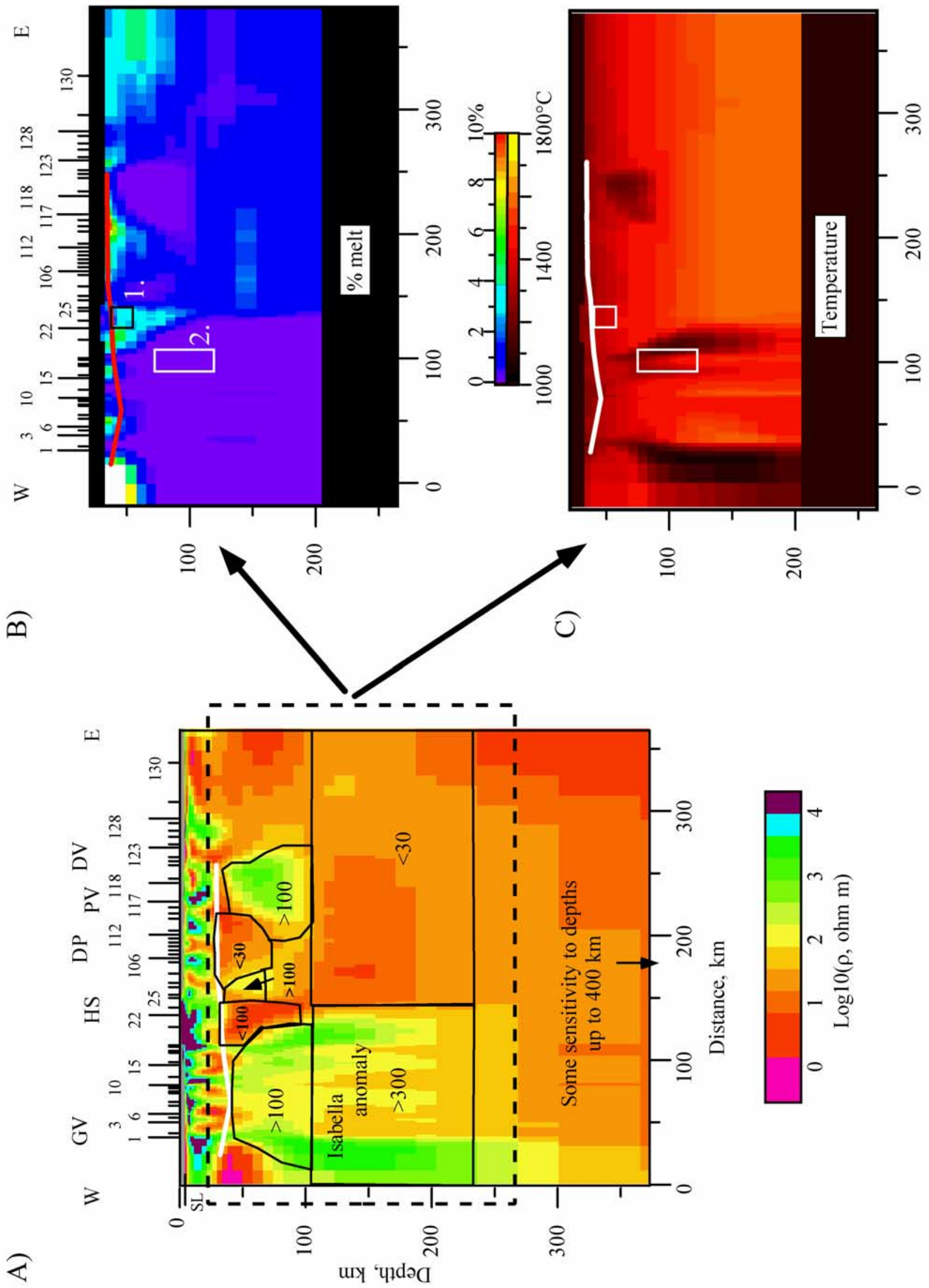

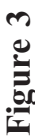



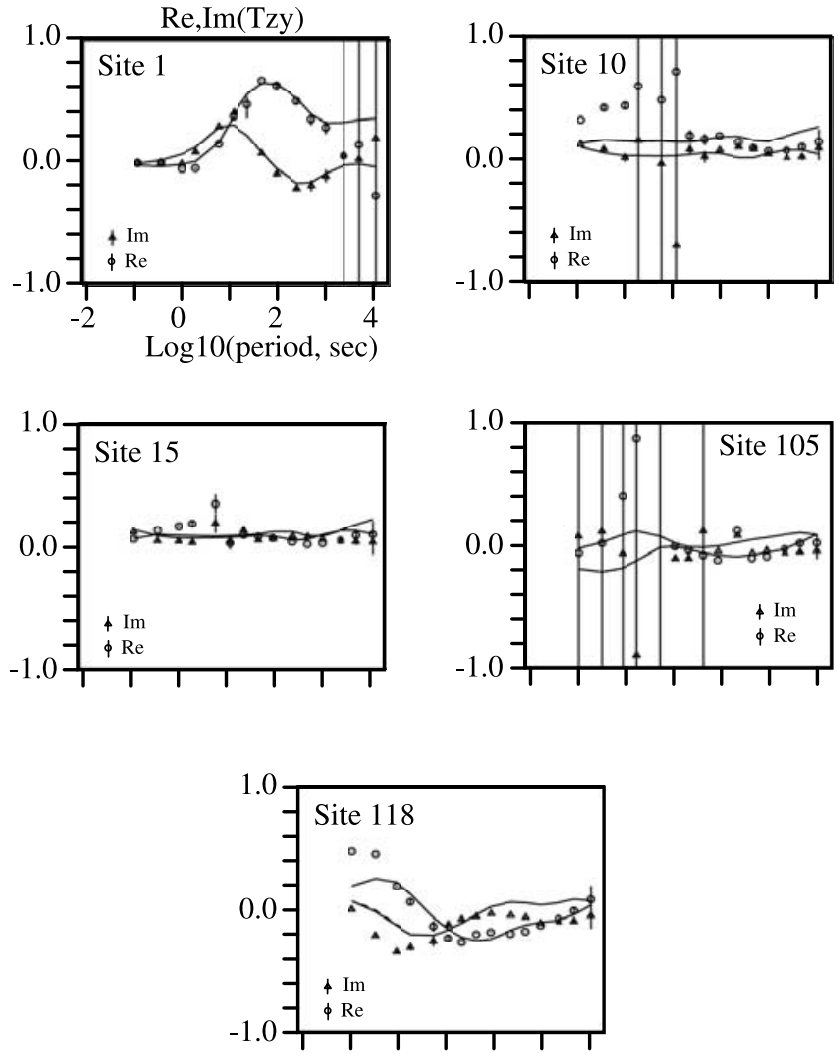

Figure 4. Comparison of observed and computed vertical field transfer functions for preferred model (Figure 3). As transfer functions are ratios of magnetic fields, they are dimensionless. Functions are plotted versus period in seconds. Error bars spanning the whole plot are at points with high noise levels. Real and imaginary components of the transfer function relating the vertical and E-W horizontal magnetic fields are shown as that is the only component modeled with a 2-D model. Site numbers correspond to those in previous figures.

deliberate and reflects the standard practices in two different scientific communities. MT studies typically result in resistivity cross sections, while laboratory studies measure conductivity (the inverse of resistivity). As this is an attempt to merge results from two disciplines, I have kept the standard terminology for each.

[22] A common method of interpreting such a section is to use a resistivity of $100 \mathrm{ohm} \mathrm{m}$ as a transition between mantle with partial melt (lower resistivities) and without partial melt (higher resistivities). In this manner, Park et al. [1996] concluded that the conductive mantle beneath the high Sierra Nevada contained several percent partial melt. Further work [Ducea and Park, 2000; Park and Ducea,
2003] refined this interpretation by proposing that sulfide melt contributes to the conductivity of this region. It is also common to infer temperature from variations in the mantle resistivity [e.g., Jones, 1992], but this is done only for mantle without partial melt because the melt is much more conductive than any of the solid phases of the matrix. In reality, the bulk conductivity is a combination of conduction through the matrix and through the melt (and possibly other conductive phases). I present a modeling approach here that transforms the resistivity section in Figure 3 into cross sections of melt fraction and temperature. It is important to note that is approach is not offered as a final answer to interpretation of MT sections, but rather as an initial framework within which to test hypotheses. The discussion below will make this point clear.

[23] Two developments have facilitated this approach. First, Ghiorso et al. [2002] developed a geochemical model (pMELTS) that predicts which mineral phases evolve from an initial bulk composition set by the user as it spans a range of pressures and temperatures. This model, based on experimentally determined thermodynamic parameters, predicts the fractions and compositions of minerals and partial melt as the given initial composition cools (or warms) at a fixed pressure. Water content and oxygen fugacity can also be controlled by the user. The solid phases consist predominantly of olivine (ol), orthopyroxene (opx), clinopyroxene (cpx), and garnet (gar). Second, Xu and Shankland. [1999] presented laboratory measurements of the conductivity of opx, cpx, and gar, and $X u$ et al. [2000a] combined these phases with earlier measurements of olivine [e.g., Shankland and Waff, 1977] to make predictions of the bulk conductivity of the lower mantle. My approach simply extends $X u$ et al.'s [2000a] work by using pMELTS to predict the volume fractions of the solid phases, rather than assuming a constant mix. I also add the effect of partial melt into the calculation of the bulk conductivity, as Roberts and Tyburczy [1999] did.

[24] The process of transforming electrical resistivity into melt fraction and temperature consists of three steps: first compute a theoretical bulk conductivity versus pressure and temperature using the petrological model and laboratory conductivity measurements; then locate the conductivitydepth pair from Figure 3 on the theoretical bulk conductivity curve; and finally determine the temperature and melt fraction that corresponds to that conductivity-depth pair. The first step consists of calculating fractions of solid phases and melt using pMELTS (Figure 6). Because I am interested in the mantle from $\sim 30$ to $\sim 200 \mathrm{~km}$, I calculated fractions over a pressure range from 1 to $6 \mathrm{GPa}$. However, Ghiorso et al. [2002] note that pMELTS has some difficulties with cpx at pressures higher than $3 \mathrm{GPa}$ and also tends to overpredict garnet and underpredict olivine at higher pressures. The extrapolations of fractions to pressures greater than $3 \mathrm{GPa}$

Figure 3. (a) Preferred electrical resistivity model from inversion of data in Figure 2. Results for sensitivity testing are shown as upper or lower bounds in regions outlined by black lines. White line is Moho from Ruppert et al. [1998]. See Figure 1 for explanation of symbols. (b) Predicted melt fractions from resistivity model. White box 1 shows location of Quaternary xenoliths indicating temperatures of $1200-1250^{\circ} \mathrm{C}$ and melt fractions of $1-3 \%$. White box 2 shows location of Miocene xenoliths with temperatures of $950-1050^{\circ} \mathrm{C}$ and no melt. (c) Predicted temperatures from resistivity model. See text for discussion of melt and temperature predictions. 


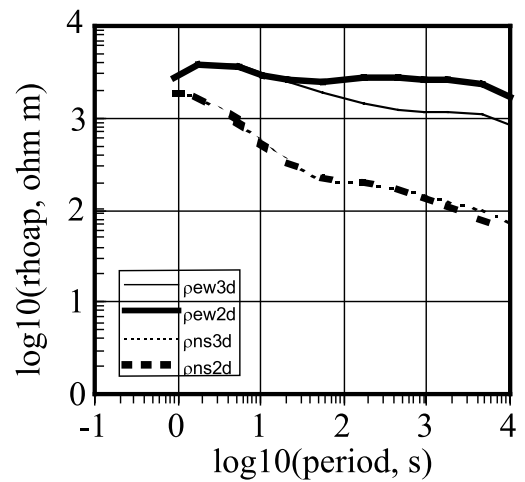

Figure 5. Comparison of 2-D and 3-D apparent resistivities in ohm meters from Isabella anomaly. Thick lines are from 2-D model, while thin lines are from 3-D model. Solid lines represent polarization perpendicular to structure, while dashed lines represent polarization parallel to structure.

( $\sim 90 \mathrm{~km}$ ) may therefore be incorrect; the divergence of the solidus and liquidus curves in Figure 6 may be an indication of this inaccuracy.

[25] The choice of starting composition affects the mineralogy of the solid, the liquidus, and the solidus. For these calculations, I began with a fertile peridotite because past studies inferred that asthenospheric mantle has been placed directly beneath the crust in the southern Sierra Nevada [e.g., Wernicke et al., 1996; Ducea and Saleeby, 1998b; Farmer et al., 2002]. Both Farmer et al. [2002] and ElkinsTanton and Grove [2003] suggest that remnants of meta-
Table 2. Initial Compositions $\mathrm{s}^{\mathrm{a}}$

\begin{tabular}{lcr}
\hline & Fertile Peridotite & Eclogite \\
\hline $\mathrm{SiO}_{2}$ & 45.47 & 46.20 \\
$\mathrm{Na}_{2} \mathrm{O}$ & 0.31 & 1.29 \\
$\mathrm{MgO}$ & 38.53 & 16.30 \\
$\mathrm{Al}_{2} \mathrm{O}_{3}$ & 4.00 & 13.90 \\
$\mathrm{P}_{2} \mathrm{O}_{5}$ & 0.00 & 0.00 \\
$\mathrm{~K}_{2} \mathrm{O}$ & 0.00 & 0.02 \\
$\mathrm{CaO}$ & 3.59 & 11.90 \\
$\mathrm{TiO}$ & 0.11 & 0.81 \\
$\mathrm{MnO}$ & 0.12 & 0.14 \\
$\mathrm{FeO}$ (total) & 7.22 & 9.30 \\
Total & 99.35 & 99.86 \\
\hline
\end{tabular}

${ }^{\mathrm{a}}$ In wt $\%$.

somatized mantle lithosphere bearing hydrous minerals (phlogopite) have been melted to produce the potassic basalts at $3.5 \mathrm{Ma}$. They show that melting occurred at depths greater than $100 \mathrm{~km}$. However, Park and Ducea [2003] present the analyses of 5 xenoliths from the Quaternary Big Pine Volcanic Field which all have $\mathrm{K}_{2} \mathrm{O}$ contents of less than $0.1 \mathrm{wt} \%$ and are much more similar to a fertile peridotite than the source of the $3.5 \mathrm{Ma}$ basalts. The MT method is sensitive only to the modern conditions, so use of a fertile peridotite as a starting composition seems reasonable (Table 2). Because I only use this model as an initial point for discussion of the inferred temperatures and melt fractions, it is not necessary to run a suite of models testing all possible initial compositions.

[26] I use the Hashin-Shtrikman (H-S) upper bound [Hashin and Shtrikman, 1962] for calculation of the matrix
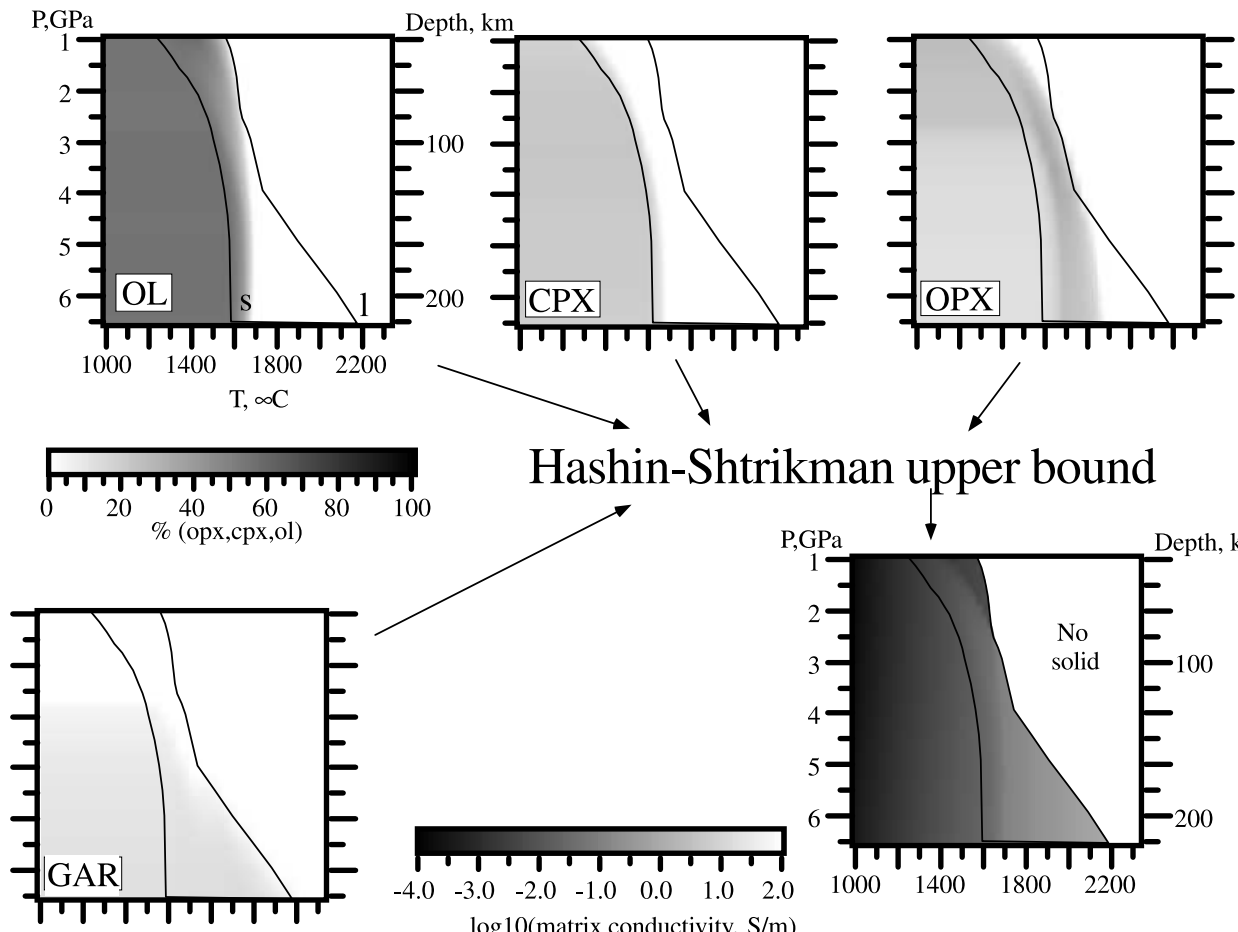

Hashin-Shtrikman upper bound

\section{0}

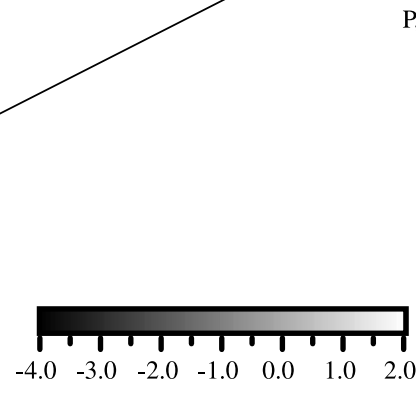

$\log 10$ (matrix conductivity, S/m)

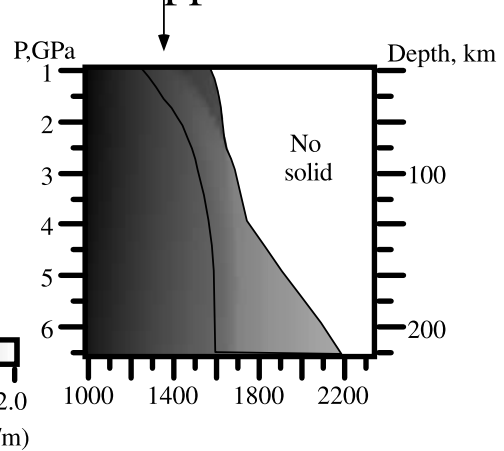

Figure 6. Computation of matrix conductivity from mineral components predicted by pMELTS. Percentages of olivine (ol), clinopyroxene (cpx), orthopyroxene (opx), and garnet (gar) are plotted versus pressure and temperature. Lines shown on each plot are solidus (s) and liquidus (1). Conductivities of each component are predicted with equations (1) and (2) and then combined with an H-S upper bound which assumes that the most conductive component (opx) is interconnected. 
Table 3. Thermodynamic Parameters for Matrix Minerals

\begin{tabular}{lrccl}
\hline Mineral & $\sigma_{0}, \mathrm{~S} / \mathrm{m}$ & $\begin{array}{c}E_{a} \text { or } E_{a 1}, \\
\mathrm{eV}\end{array}$ & \multicolumn{1}{c}{$E_{a 2}, \mathrm{eV}$} & \multicolumn{1}{c}{ Source } \\
\hline $\mathrm{ol}$ & & 1.60 & 4.25 & Constable et al. $[1992]$ \\
$\mathrm{opx}$ & 5,248 & 1.80 & & Xu and Shankland [1999] \\
$\mathrm{cpx}$ & 1,778 & 1.87 & & Xu and Shankland [1999] \\
gar & 2,239 & 1.66 & & Xu and Shankland [1999] \\
Melt & 18,400 & 1.15 & & Shankland and Waff [1977] \\
\hline
\end{tabular}

conductivity from predictions of the volume phases (Figure 6). The conductivity of each phase is represented by [Constable et al., 1992]

$$
\begin{gathered}
\sigma_{\text {olivine }}=10^{2.4} \exp \left(-E_{a 1} / k T\right)+10^{9.17} \exp \left(-E_{a 2} / k T\right) \\
\sigma_{\text {opx }, \text { gar,cpx }, \text { melt }}=\sigma_{0} \exp \left[-E_{a} / k T\right],
\end{gathered}
$$

where $k$ is the Boltzmann constant and $T$ is the absolute temperature in $\mathrm{K}$. The preexponential terms and activation energies are taken from various sources given in Table 3. Equation (1) neglects the pressure dependence of olivine conductivity because $X u$ et al. [2000b] concluded that this was only needed for depths greater than $200 \mathrm{~km}$. For the matrix components, opx is the most conductive fraction [Xu and Shankland, 1999], and Park and Ducea [2003] showed that the H-S upper bound matched the measured conductivity of a lherzolite at atmospheric pressure [Constable and Duba, 1990, Figure 4] to within 10\%. (An older equation for olivine from Shankland and Waff
[1977] was also tested, but the matrix conductivities differed by less than $1-2 \%$ because opx conductivity dominates the solid matrix.) I therefore conclude that the $\mathrm{H}-\mathrm{S}$ upper bound using opx as the most conductive phase is an appropriate choice for the matrix conductivity.

[27] The matrix conductivity is now combined with the melt fraction and predictions of melt conductivity using equation (2) to yield bulk conductivity versus pressure and temperature (Figure 7). I assume that the melt fraction forms an interconnected network. Because the melt is much more conductive than the matrix, these two components are again combined with an H-S upper bound. The resulting bulk conductivity (Figure 7) has the desirable property that the change in conductivity with temperature is monotonic for a given pressure. Thus a unique temperature can be identified for each conductivity-depth pair from Figure 3.

[28] The second step in the transformation process is to determine the pressure and temperature for each conductivity-depth pair in the resistivity model (conductivity of a cell is the inverse of its resistivity). The pressure is estimated from the depth with a simple factor of $30 \mathrm{~km}$ per $1 \mathrm{GPa}$. Once a conductivity-pressure pair is plotted on the bulk conductivity prediction, a temperature can be determined (Figure 7). The last step in the transformation is to determine melt fraction from the pressure-temperature pair (Figure 7). When the transformation is completed for every cell in the model, cross sections of temperature and melt fraction result (Figure 3).

[29] The sections in Figure 3 represent a step toward geologically more useful images than the resistivity section (Figure 3), but comparison to xenoliths is necessary in order

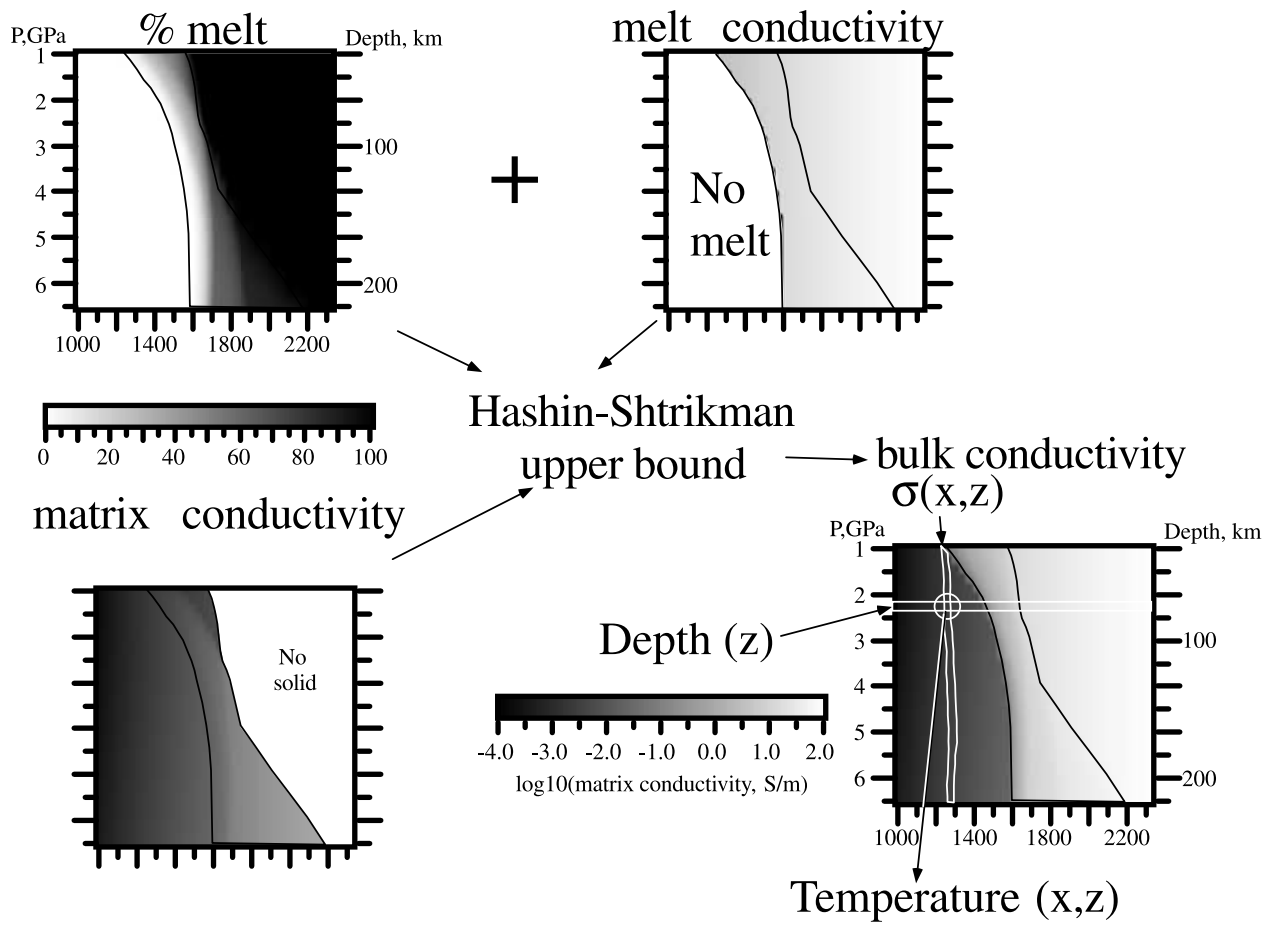

Figure 7. Computation of bulk conductivity from matrix conductivity, melt fraction, and melt conductivity. Use of H-S upper bound implies melt is an interconnected phase in the model. Conductivity-depth pairs from Figure 3 are plotted on the bulk conductivity map in order to extract temperature. Pressure and temperature are then used to determine melt fraction. 
to assess how well these predictions match the subsurface. None of these xenoliths have been sampled along the MT profile, however (e.g., Kern Volcanic Field, Figure 1), so projection of the xenolith localities onto the temperature and melt fraction sections was necessary and may be slightly inaccurate. Nonetheless, these projections are accurate enough to assess how well this transformation works. Miocene peridotitic xenoliths generally yielded temperatures of $950-1050^{\circ} \mathrm{C}$ at pressures of $2.2-$ 3.6 $\mathrm{GPa}$, while the Pliocene and Quaternary xenoliths showed temperatures of $1175-1250^{\circ} \mathrm{C}$ at pressures of 0.8-2 GPa [Ducea and Saleeby, 1996, 1998b]. The Quaternary xenoliths lie above the dry peridotite solidus [Park and Ducea, 2003], and some primary melt inclusions were found [Ducea and Saleeby, 1998a]. Boxes outlining the approximate locations of these xenoliths are shown on the temperature and melt fraction sections (Figure 3). Note that the region of $>10 \%$ partial melt on the extreme western edge of the section results from very low resistivities in a region unconstrained by any $\mathrm{MT}$ data and is likely an artifact of the inversion.

\section{Discussion}

[30] My transformation predicts temperatures of 1150$1250^{\circ} \mathrm{C}$ and no melt where the Miocene xenoliths presumably originated and temperatures of $1400-1450^{\circ} \mathrm{C}$ and $\sim 3 \%$ melt where the Quaternary xenoliths originated. The mismatch in temperatures for the Miocene xenoliths may be due to changes in the lithosphere between Miocene and present, but the Quaternary xenoliths and the MT section presumably sense the same mantle. I thus conclude that while melt fractions are approximately correct, temperatures appear to be overestimated by $\sim 200^{\circ} \mathrm{C}$. Very little melt is now found except in the shallow portions of the mantle to the east of the Kern River fault (Figure 3). Melt in the shallow mantle appears to match well with basalt flows in and around the High Sierra (stations 20-25; Figure 3), Darwin Plateau (stations 106-117), and Death Valley (stations 120-123).

[31] Temperatures appear to be overestimated both in places where melt is present and where melt is absent. If this problem were only in regions with partial melt, then addition of volatiles such as water to lower the liquidus would be a viable explanation for the discrepancy. A small amount of water could reduce the liquidus and temperatures for a given melt fraction would be lower. However, small amounts of water do not explain the temperature discrepancy in regions where melt is absent. Because the temperatures appear to be overestimated in regions where melt is absent, explanations that affect the matrix conductivity need to be considered.

[32] The transformation of the MT-derived resistivity section results in temperatures that are approximately $200^{\circ} \mathrm{C}$ higher than those inferred from xenoliths. Reduction of the temperatures estimated from the matrix conductivity (Figure 8 ) by $200^{\circ} \mathrm{C}$ would require that the matrix be $\sim 7$ times more conductive for a given temperature. Simultaneously, the melting temperature cannot be shifted substantially or the partial melt fractions will be too high. Possible explanations for this temperature discrepancy include hydrous minerals, incorrect starting composition for

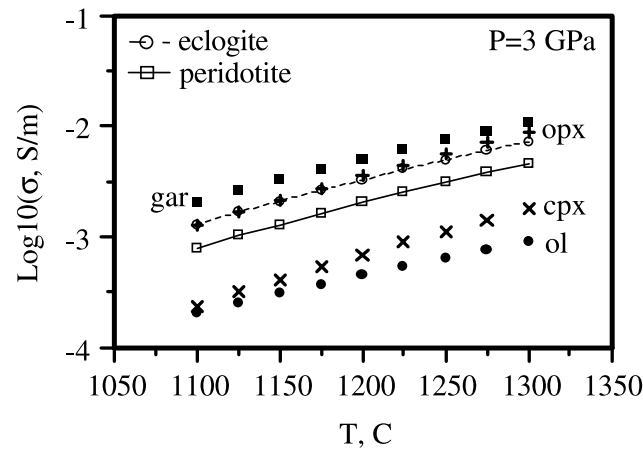

Figure 8. Constituent conductivities computed using equations (1) and (2) with coefficients in Table 3 for a pressure of $3 \mathrm{GPa}$ and subsolidus temperatures. Also shown are bulk conductivities for eclogite and peridotite using mineral fractions predicted from pMELTS. Note that garnet (gar) and orthopyroxene (opx) are the two most conductive fractions.

pMELTS, exotic melts, incorrect estimation of the bulk conductivity from components, high oxygen concentration, high iron content, and excess concentrations of diffusing ions through the solid matrix.

[33] Pliocene high potassic basalts [Farmer et al., 2002] and xenoliths [Elkins-Tanton and Grove, 2003] have led to suggestions that these $3.5 \mathrm{Ma}$ basalts were created by melting of sinking remnants of metasomatized mantle lithosphere at depths greater than $100 \mathrm{~km}$. These remnants contain hydrous minerals (phlogopite) that lower the melting temperature and would lead to an increase in the partial melt fraction estimated for a given depth and conductivity. While use of metasomatized mantle as the starting material would lower the temperature estimated for a given depth and conductivity, it would also raise the partial melt fraction throughout the section. Farmer et al. [2002] also show that the fragments of metasomatized mantle are not widespread. Additionally, the Quaternary xenoliths show no evidence of metasomatism [Park and Ducea, 2003]. Thus I conclude that metasomatized mantle is a not viable explanation for the temperature discrepancy for the entire section.

[34] Basaltic melts have been extracted from the mantle since Miocene times [Manley et al., 2000], and it is possible that depleted peridotite is a more appropriate starting composition. An initial depleted composition would raise the melting temperature for a given pressure and thus lower estimates of melt fraction for a given temperature. Partially melting a fertile peridotite and then extracting melt would leave the residue relatively enriched in opx (Figure 6), thus raising the overall matrix conductivity because opx is the most conductive component of the matrix (Figure 8). Both of these potential changes are possibly acceptable, but are the magnitudes sufficient to explain the observed discrepancy in temperature? I tested this by transforming the MT resistivity model using bulk conductivity-pressure-temperature relations calculated for a starting material of depleted peridotite. Oxide ratios from Anderson [1989] for peridotite with $20 \%$ melt already extracted were chosen for the depleted mantle because Ducea et al. [1998] estimate $10-30 \%$ partial melting was needed to produce the eclogitic 
residue beneath the Sierra Nevada. Estimated melt fractions using the depleted peridotite model are indeed lower than those in Figure 3, but estimated temperatures are $30^{\circ} \mathrm{C}$ higher than those from the fertile peridotite model. Thus the overestimated temperatures in Figure 3 cannot be explained by the difference in using a fertile versus depleted peridotite as a starting material.

[35] Ducea and Park [2000] and Park and Ducea [2003] have suggested that the enhanced conductivity beneath the High Sierra could be due to a mix of basaltic and metallic sulfide melts. Addition of $<0.1 \%$ sulfide melt as blebs could lower the estimate of basaltic melt needed to explain the conductivity anomaly from $3-5 \%$ to $<1 \%$, a result more consistent with other petrological evidence [Park and Ducea, 2003]. While sulfide melt could contribute to the conductivity of the partially melted regions (Figure 3 ), it seems unlikely that it would be present throughout the section. Even if the sulfide melt were pervasive because temperatures are generally above its solidus, it forms isolated blebs and cannot contribute significantly to bulk conductivity unless it is connected by the basaltic melt [Park and Ducea, 2003]. Thus I conclude that sulfide melt cannot explain the temperature discrepancy.

[36] Carbon films have been suggested to enhance mantle conductivity [Duba and Shankland, 1982]. Recently, Jones et al. [2001] attributed anomalously high $(>0.03 \mathrm{~S} / \mathrm{m})$ mantle conductivity beneath the Slave craton at depths of $80-100 \mathrm{~km}$ to carbon. However, Tsong et al. [1985] show that the diffusivity of carbon is low in olivine and thus relatively immobile. Unless a $\mathrm{CO}_{2}$-rich fluid is percolating through the mantle and depositing a carbon film, it is unlikely that carbon could be contributing to higher mantle conductivities. Note that such a fluid would be resistive and would not lower the bulk conductivity.

[37] Bulk conductivity could be incorrectly estimated from the conductivities of the individual elements. Melt has the highest conductivity of any of the components so errors this component are more likely to affect the transformation than the solid minerals. In the absence of melt, Park and Ducea [2003] showed that the H-S upper bound with opx as the most conductive element adequately represented the matrix conductivity of a lherzolite with no melt. Equation (2), which was used for the melt conductivity, was derived from measurements of melt as temperature was varied [Shankland and Waff, 1977]. Roberts and Tyburczy [1999] showed that under conditions of batch melting, the melt composition changes so that its conductivity does not vary as much as that predicted by equation (2). Indeed, they concluded that the melt conductivity was relatively constant at $0.8 \mathrm{~S} / \mathrm{m}$.

[38] Tests of the transform with a constant melt conductivity of $0.8 \mathrm{~S} / \mathrm{m}$ resulted in temperature estimates that were $30-50^{\circ} \mathrm{C}$ higher than those shown in Figure 3. A more serious problem is that melt fractions are much higher than those using equation (2). Most of the section below $100 \mathrm{~km}$ had melt fractions above $10 \%$, and values exceeded $40 \%$ locally. I thus conclude that the melt has to be more conductive than $0.8 \mathrm{~S} / \mathrm{m}$ if low melt fractions from the xenoliths must be matched.

[39] The conductivities of the individual components of the peridotite could also be underestimated. Conduction in solid olivine at these pressures and temperatures is controlled primarily by migration of defects through the crystal lattice. Conduction due to polaron migration is the controlling factor for olivine conduction [Hirsch and Shankland, 1993; Shock et al., 1989], although Constable and Roberts [1997] found that contributions from electron and magnesium vacancy conduction were needed to explain olivine conductivity and thermopower measurements. Polaron conduction is via hole migration from $\mathrm{Fe}^{2+}$ to $\mathrm{Fe}^{3+}$ at sites where iron has replaced magnesium in the crystal lattice. Higher oxygen concentrations enhance the substitution of iron for magnesium [Hirsch and Shankland, 1993]. Both oxygen fugacity and iron content will thus alter the conductivity of olivine. Shock et al. [1989] showed that electrical conductivity of olivine could be increased by 10 times if the oxygen fugacity increased by 5.5 orders of magnitude, so a sevenfold increase in matrix conductivity could be explained by an increase in oxygen concentration by 4 orders of magnitude. The fertile peridotite model used to derive the sections in Figure 3 was run using a QFM buffer because this is the expected oxidation state of the mantle [Arculus, 1985]. Nonetheless, I computed a new model with QFM+3 (an increase of 3 orders of magnitude in oxygen concentration) to allow for the possibility that the oxidation state may be different. Upon transforming the MT section again, I obtained low melt fractions that matched the xenolith data $(2 \%$ for region 1 and $0 \%$ for region 2 , Figure 3). Temperatures for Quaternary xenoliths were still overestimated by $200^{\circ} \mathrm{C}$, although they matched for the Miocene ones. It is thus possible that the overestimated temperatures in melt-free regions could be explained by an increase in oxygen concentration, but modeled temperatures in partially melted regions are still too high.

[40] Iron increases the conductivity of olivine by increasing small polaron formation and thus facilitating migration of holes. Hirsch et al. [1993] showed that olivine conductivity increased as $[\mathrm{Fe} /(\mathrm{Fe}+\mathrm{Mg})]^{1.8}$. Given the starting models in Table 2, the ratio of $\mathrm{Fe}$ to $(\mathrm{Fe}+\mathrm{Mg})$ varied from a low of 0.02 to a high of 0.09 for fertile peridotite as the oxygen fugacity varied from 3 orders of magnitude higher than the QFM buffer to 5 orders of magnitude lower. All other compositions tested (fertile and depleted peridotite, eclogite) fell between these values. The fertile peridotite used to generate Figure 3 had a ratio of 0.04 , so it is possible that the olivine conductivity could have been underestimated by as much as a factor of $(0.09 / 0.04)^{1.8}=4$. Even if olivine were the dominant conducting fraction in the matrix, this factor is still too small to explain the entire temperature discrepancy. Nonetheless, future refinements of the petrological modeling could include the effect of iron concentration because pMELTS computes the relative proportions of iron and magnesium in olivine.

[41] Conductivity of solid olivine can also be enhanced by diffusion of ions such as carbon, oxygen, and hydrogen [e.g., Karato, 1990], but the diffusion of hydrogen through olivine is 8 orders of magnitude faster than oxygen [Mackwell and Kohlstedt, 1990] and 4 orders of magnitude faster than carbon [Tsong et al., 1985]. Karato [1990] postulated that conductivity could be enhanced tenfold with $100 \mathrm{H} / 10^{6} \mathrm{Si}$ dissolved in olivine crystals based on measurements of hydrogen diffusion coefficients. T. J. Shankland and A. G. Duba (The role of carbon and temperature in determining the electrical conductivity of 
basins, crust, and mantle, in Geoscience Research Program Annual Summaries FY96, 1996, available at www.sc.doe. gov/production/bes/geo/Publications/FY96Summ/ sect3.htm) measured enhanced conductivity in olivine with small hydrogen concentrations, although extrapolation of his measurements indicates that $100 \mathrm{H} / 10^{6} \mathrm{Si}$ increases conductivity by only a factor of 3.5 . A concentration less than $70-$ $200 \mathrm{H} / 10^{6} \mathrm{Si}$ could thus provide our needed sevenfold increase in matrix conductivity. This is an amount comparable to that seen in mid-ocean ridge basalt (MORB) sources [Bell and Rossman, 1992], so the concentration is reasonable. [42] A source for hydrogen is also readily available. Prior to $\sim 80 \mathrm{Ma}$, the Sierra Nevada was a volcanic arc formed by subduction of the Farallon plate beneath the North American plate [Saleeby et al., 1986]. While batholithic formation ceased $\sim 80 \mathrm{Ma}$, subduction continued until the Farallon plate was consumed and the current transform margin (the San Andreas fault) began forming at $\sim 30 \mathrm{Ma}$ [Atwater, 1989]. Most modern models of subduction generate the magma from a mantle wedge metasomatized by fluids liberated from the subducting plate [e.g., Peacock, 1993]. Thus metasomatized mantle existed beneath the Sierra Nevada until $\sim 4 \mathrm{Ma}$ when the lower lithosphere delaminated [Manley et al., 2000]. Sinking lithospheric fragments could melt [e.g., ElkinsTanton and Grove, 2003], liberating fluids that could percolate up into the encroaching asthenospheric mantle directly beneath the Sierran crust. Thus a modestly hydrated asthenospheric mantle could explain the temperature discrepancy.

[43] The Isabella anomaly appears clearly in the temperature section as a cooler region (Figure 3). This body is inferred to be eclogitic, however; so a petrologic model using peridotite as a starting composition likely predicts temperatures incorrectly. Eclogite consists primarily of garnet and clinopyroxene, and garnet is one of the more conductive phases (Figure 8). The peridotitic matrix will thus be less conductive for a given temperature than would the eclogitic matrix, and the predicted temperature for a given conductivity would be $\sim 75^{\circ} \mathrm{C}$ higher with the peridotitic matrix model than that with the eclogitic matrix (Figure 8). This could explain why temperatures are overestimated in the Isabella anomaly, but not elsewhere in the cross section. If compositional differences are ignored, the model predicts a $200-250^{\circ} \mathrm{C}$ increase in the Basin and Range mantle compared to the Isabella anomaly. Such an increase is consistent with earlier estimates of temperature differences from xenoliths; peridotic xenoliths are garnet-bearing to the west and garnet-free to the east [Ducea and Saleeby, 1996]. The western boundary of the Isabella anomaly also appears in the temperature section, but it is only weakly constrained by data and the electrical anomaly may extend westward. The Isabella anomaly is characterized by a compressional wave speed increase of at least 3\% and has been cited as evidence of a delaminating eclogitic root to the Sierra Nevada because of its high velocity [e.g., Zandt, 2003]. Humphreys and Duecker [1994] have estimated that this wave speed increases $0.6 \%$ for each $100^{\circ} \mathrm{C}$ temperature decrease. Thus a $200^{\circ} \mathrm{C}$ temperature decrease could result in a $1.2 \%$ velocity increase independent of any compositional changes. Only some of the velocity anomaly could be attributed to temperature differences; the remainder must be due to compositional differences.

\section{Conclusions}

[44] Using a total of 54 broadband MT soundings and 12 long-period stations spanning $300 \mathrm{~km}$, a 2-D model that is optimized for mantle structure has been inverted. The resulting cross section of electrical resistivity reveals a heterogeneous mantle between Moho at 30-35 km and depths of $\sim 240 \mathrm{~km}$. While much of the section has resistivities low enough $(<100 \mathrm{ohm} \mathrm{m})$ to infer partial melt, a transformation using petrological models and laboratory measurements allows separation of conductivity variations from increasing temperature and from partial melt. The melt section derived in this manner reveals that partial melt is relatively uncommon beneath the Sierra Nevada and California Basin and Range. In particular, melt in the shallow mantle is predicted only beneath regions where basalt has erupted since Miocene times. Further, predicted partial melt fractions of a few percent are consistent with estimates from xenoliths.

[45] The temperature model overestimates matrix temperature by $\sim 200^{\circ} \mathrm{C}$, which could result from uniformly underestimating the matrix conductivity by a factor of $\sim 7$. The two most likely explanations for an increase in matrix conductivity are higher oxygen concentrations or hydrogen diffusion. I favor hydrogen diffusion because of its high diffusivity in olivine and because it would be readily available from sinking and melting delaminated lithosphere. I infer that the asthenospheric mantle beneath the Sierra Nevada and California Basin and Range is only modestly hydrated; concentrations are comparable to those seen at ocean ridges.

[46] Zandt [2003] has suggested that the Isabella velocity anomaly is the delaminating eclogitic lithosphere formerly beneath the High Sierra. This high wave speed body also has higher resistivities that I attribute to lower temperatures. The eastern, upper, and lower boundaries of this body appear clearly in the resistivity section, but the western boundary is only weakly constrained by the MT data.

[47] Acknowledgments. This project was supported by grant EAR9526992 from the National Science Foundation's Continental Dynamics Program and by grant EAR0073707. Any opinions, findings, and conclusions or recommendations are those of the author and do not necessarily reflect the views of the National Science Foundation. Long-period instruments from the EMSOC instrument pool were used in 1997. I also thank Randall Mackie, Peter Molnar, and Jeffery Roberts for their thoughtful comments on this manuscript. Reviews by Frank Schilling and Phillip Wannamaker greatly improved this manuscript.

\section{References}

Anderson, D. L. (1989), Theory of the Earth, Blackwell Sci., Malden, Mass.

Arculus, R. J. (1985), Oxidation status of the mantle: Past and present, Annu. Rev. Earth Planet. Sci, 13, 75-95.

Atwater, T. (1989), Plate tectonic history of the northeast Pacific and western North America, in The Geology of North America, vol. N, The Eastern Pacific Ocean and Hawaii, edited by E. L. Winterer, D. M. Hussong, and R. W. Decker, pp. 21-72, Geol. Soc. of Am., Boulder, Colo.

Bell, D. R., and G. R. Rossman (1992), Water in the Earth's mantle: The role of nominally anhydrous minerals, Science, 255, 1391-1397.

Benz, H. M., and G. Zandt (1993), Teleseismic tomography: Lithospheric structure of the San Andreas Fault system in northern and central California, in Seismic Tomography: Theory and Practice, edited by H. M. Iyer and K. Hirahara, pp. 440-465, Chapman and Hall, New York. 
Berdichevsky, M. N., V. I. Dmitriev, and E. E. Pozdnjakova (1998), On two-dimensional interpretation of magentotelluric soundings, Geophys. J. Int., 133, 585-606.

Bird, P. (1978), Initiation of intracontinental subduction in the Himalaya, J. Geophys. Res., 83, 4975-4987.

Chave, A. D., D. J. Thomson, and M. E. Ander (1987), On the robust estimation of power spectra, coherences, and transfer functions, J. Geophys. Res., 92, 633-648.

Constable, S., and A. Duba (1990), Electrical conductivity of olivine, a dunite, and the mantle, J. Geophys. Res., 95, 6967-6978.

Constable, S., and J. J. Roberts (1997), Simultaneous modeling of thermopower and electrical conduction in olivine, Phys. Chem. Miner. 24, 319-325

Constable, S., T. Shankland, and A. Duba (1992), The electrical conductivity of an isotropic olivine mantle, J. Geophys. Res., 97(B3), 3397-3404

Duba, A. G., and T. J. Shankland (1982), Free carbon and electrical conductivity in the Earth's mantle, Geophys. Res. Lett., 9, 1271-1274.

Ducea, M. N. (2002), Constraints on the bulk composition and root foundering rates of continental arcs: A California arc perspective, J. Geophys. Res., 107(B11), 2304, doi:10.1029/2001JB000643.

Ducea, M. N., and S. K. Park (2000), Enhanced mantle conductivity from sulfide minerals, southern Sierra Nevada, California, Geophys. Res. Lett. $27,2405-2408$

Ducea, M. N., and J. B. Saleeby (1996), Buoyancy sources for a large, unrooted mountain range, the Sierra Nevada, California; evidence from xenolith thermobarometry, J. Geophys. Res., 101, 8229-8244.

Ducea, M., and J. Saleeby (1998a), Crustal recycling beneath continental arcs: Silica-rich glass inclusions in ultramafic xenoliths from the Sierra Nevada, California, Earth Planet. Sci. Lett., 156, 101-116.

Ducea, M., and J. Saleeby (1998b), A case for delamination of the deep batholithic crust beneath the Sierra Nevada, California, Int. Geol. Rev., 40, 78-93

Ducea, M., J. Saleeby, and J. Taylor (1998), Eclogitic residues from beneath the Sierra Nevada: Similarities between the extraction of Cordilleran and Archean granitoids, Geol. Soc. Am. Abstr. Programs, 30, 258.

Elkins-Tanton, L. T., and T. L. Grove (2003), Evidence for deep melting of hydrous metasomatized mantle: Pliocene high-potassium magmas from the Sierra Nevadas, J. Geophys. Res., 108(B7), 2350, doi:10.1029/ 2002JB002168.

Farmer, G. L., A. F. Glazner, and C. R. Manley (2002), Did lithospheric delamination trigger late Cenozoic potassic volcanism in the southern Sierra Nevada, California?, Geol. Soc. Am. Bull., 114, 754-768.

Fliedner, M. M., et al. (1996), Three-dimensional crustal structure of the southern Sierra Nevada from seismic fan profiles and gravity modeling, Geology, 24, 367-370.

Ghiorso, M. S., M. M. Hirschmann, P. W. Reiners, and V. C. Kress III (2002), The pMELTS: A revision of MELTS for improved calculation of phase relations and major element partitioning related to partial melting of the mantle to $3 \mathrm{GPa}$, Geochem. Geophys. Geosyst., 3(5), 1030, doi:10.1029/2001GC000217.

Groom, R. W., and R. C. Bailey (1989), Decomposition of magnetotelluric impedance tensors in the presence of local three-dimensional galvanic distortion, J. Geophys. Res., 94, 1913-1925.

Hashin, Z., and S. Shtrikman (1962), A variational approach to the theory of effective magnetic permeability of multiphase materials, J. Appl. Phys., $33,3125-3131$

Hirsch, L. M., and T. J. Shankland (1993), Quantitative olivine-defect chemical model: Insights on electrical conduction, diffusion, and role of Fe content, Geophys. J. Int., 114, 21-35.

Hirsch, L. M., T. J. Shankland, and A. G. Duba (1993), Electron conduction and polaron mobility in Fe-bearing olivine, Geophys. J. Int., 114, 36-44.

Houseman, G. A., D. P. McKenzie, and P. Molnar (1981), Convective instability of a thickened boundary layer and its relevance for the thermal evolution of continental convergent belts, J. Geophys. Res., 86, 61156132.

Humphreys, E. D., and K. G. Dueker (1994), Physical state of the western U.S. upper mantle, J. Geophys. Res., 99, 9635-9650.

Jones, A. G. (1992), Electrical conductivity of the continental lower crust, in Continental Lower Crust, edited by D. M. Fountain, R. J. Arculus, and R. W. Kay, pp. 81-143, Elsevier Sci., New York.

Jones, A. G., I. J. Ferguson, A. D. Chave, R. L. Evans, and G. W. McNiece (2001), Electric lithosphere of the Slave craton, Geology, 29, 423-426.

Jones, C. H., H. Kanamori, and S. W. Roecker (1994), Missing roots and mantle "drips": Regional Pn and teleseismic arrival times in the southern Sierra Nevada and vicinity, California, J. Geophys. Res., 99, 4567-4601.

Karato, S. (1990), The role of hydrogen in the electrical conductivity of the upper mantle, Nature, 347, 272-273.

Mackwell, S. J., and D. L. Kohlstedt (1990), Diffusion of hydrogen in olivine: Implications for water in the mantle, J. Geophys. Res., 95, 5079-5088
Manley, C. R., A. F. Glazner, and G. L. Farmer (2000), Timing of volcanism in the Sierra Nevada of California: Evidence for Pliocene delamination of batholithic root?, Geology, 28, 811-814.

Park, S. K., and M. N. Ducea (2003), Can in situ measurements of mantle electrical conductivity be used to infer properties of partial melts?, J. Geophys. Res., 108(B5), 2270, doi:10.1029/2002JB001899.

Park, S. K. and B. Wernicke (2003), Electrical conductivity images of Quaternary faults and Tertiary detachments in the California Basin and Range, Tectonics, 22(4), 1030, doi:10.1029/2001TC001324.

Park, S. K., R. W. Clayton, M. N. Ducea, C. H. Jones, S. D. Ruppert, and B. Wernicke (1995), Project combines seismic and magnetotelluric surveying to address the Sierran root question, Eos Trans. $A G U, 76$, 297-298.

Park, S. K., B. Hirasuna, G. R. Jiracek, and C. Kinn (1996), Magnetotelluric evidence of lithospheric thinning beneath the southern Sierra Nevada, J. Geophys. Res., 101, 16,241-16,255.

Peacock, S. M. (1993), Large-scale hydration of the lithosphere above subducting slabs, Chem. Geol., 108, 49-59.

Roberts, J. J., and J. A. Tyburczy (1999), Partial-melt electrical conductivity: Influences of melt composition, J. Geophys. Res., 104, 7055-7065.

Rodi, W. L., and R. L. Mackie (2001), Nonlinear conjugate gradients algorithm for 2-D magnetotelluric inversion, Geophysics, 66, 174-187.

Ruppert, S., M. M. Fliedner, and G. Zandt (1998), Thin crust and active upper mantle beneath the southern Sierra Nevada in the western United States, Tectonophysics, 286, 237-252.

Saleeby, J. B., et al. (1986), Continental-ocean transect: C-2 central California offshore to Colorado Plateau, Centennial Continent Ocean Transect. Map 10, 1:500,000, Geol. Soc. of Am., Boulder, Colo.

Saltus, R. W., and A. H. Lachenbruch (1991), Thermal evolution of the Sierra Nevada: Tectonic implications of new heat flow data, Tectonics, 10, 325-344

Schmucker, U. (1970), Anomalies of geomagnetic variations in the southwest United States, Ph.D. dissertation, Univ. of Calif., San Diego.

Shankland, T. J., and H. S. Waff (1977), Partial melting and electrical conductivity anomalies in the upper mantle, J. Geophys. Res., 82, 5409-5417.

Shock, R. N., A. G. Duba, and T. J. Shankland (1989), Electrical conduction in olivine, J. Geophys. Res., 94, 5829-5839.

Smith, J. T., and J. R. Booker (1991), Rapid inversion of two- and threedimensional magnetotelluric data, J. Geophys. Res., 96, 3905-3922.

Swift, C. M. (1967), A magnetotelluric investigation of an electrical conductivity anomaly in the southwestern United States. Ph.D. dissertation, Mass. Inst. of Technol., Cambridge.

Tsong, I. S. T., U. Knipping, C. M. Loxton, C. W. Magee, and A. W. Arnold (1985), Carbon on surfaces of magnesium oxide and olivine single crystals: Diffusion from the bulk or surface contamination?, Phys. Chem. Miner., 12, 261-270

Vozoff, K. (1991), The magnetotelluric method, in Electromagnetic Methods in Applied Geophysics, edited by M. N. Nabighian, pp. $641-$ 711, Soc. of Explor. Geophys., Tulsa, Okla.

Wannamaker, P. E. (1999), Affordable magnetotellurics: Interpretation in natural environments, in Three-Dimensional Electromagnetics, Geophys. Dev. Ser., vol. 7, edited by M. Oristaglio and B. Spies, pp. 349-374, Soc. of Explor. Geophys., Tulsa, Okla.

Wannamaker, P. E., P. E. Rose, W. M. Doerner, B. C. Berand, J. McCulloch, and K. Nurse (2004), Magnetotelluric surveying and monitoring at the Coso geothermal area, California, in support of the enhanced geothermal systems concept: Survey parameters and initial results, paper presented at 29th Workshop on Geothermal Reservoir Engineering, Stanford Univ., Stanford, Calif., 26-28 Jan.

Wernicke, B., et al. (1996), Origin of high mountains in the continents: The southern Sierra Nevada, Science, 271, 190-193.

Xu, Y., and T. J. Shankland (1999), Electrical conductivity of orthopyroxene and its high pressure phases, Geophys. Res. Lett., 26, 26452648.

Xu, Y., T. J. Shankland, and B. T. Poe (2000a), Laboratory-based electrical conductivity in the Earth's mantle, J. Geophys. Res., 105, 27,86527,875 .

Xu, Y., T. J. Shankland, and A. G. Duba (2000b), Pressure effect on electrical conductivity of mantle olivine, Phys. Earth Planet. Inter., 118, $149-161$

Zandt, G. (2003), The southern Sierra Nevada drip and the mantle wind direction beneath the southwestern United States, Int. Geol. Rev., 45, $213-244$

S. K. Park, Institute of Geophysics and Planetary Physics, University of California, 1432 Geology, Riverside, CA 92521, USA. (magneto@ucrmt. ucr.edu) 